\section{Commentary: Rodent model of myocardial autophagy after ventriculoplasty for ischemic cardiomyopathy: Not ready for prime time yet}

\author{
Darrell Wu, MD, ${ }^{\mathrm{a}}$ and Shuab Omer, $\mathrm{MD}^{\mathrm{b}}$
}

The concept of autophagy as a vital metabolic process to recycle degradation products, maintain cellular function, and provide quality control is not new. Misfolded, senescent, or damaged proteins and organelles, via autophagosome formation, are catabolized by lysosomes into amino acids or fatty acids for further use. ${ }^{1}$ However, the role of autophagy in cardiovascular sciences remains in its infancy. Conflicting literature indicates that canonical activation can be protective, whereas noncanonical activation of autophagy can be maladaptive after myocardial infarction and affect myocardial remodeling. ${ }^{2}$ These differences can be explained by the wide biology of autophagy in mitochondrial dysfunction, apoptosis, inflammation, atherosclerosis, aneurysm formation, ischemia-reperfusion response, and myocardial development and remodeling. ${ }^{3}$ In this issue of the Journal, Sugimoto and colleagues ${ }^{4}$ have attempted to examine how autophagy affects the myocardium after left ventriculoplasty in a rat model of ischemic cardiomyopathy.

Sugimoto and colleagues ${ }^{4}$ used 10-week-old SpragueDawley rats that underwent left anterior descending artery (LAD) ligation with or without left ventriculoplasty (LVP) and followed the rats that underwent LVP for an additional 2 or 28 days. They found that in the group that underwent LAD ligation and LVP, the LC3-II expression, an

\footnotetext{
From the ${ }^{\text {a Division }}$ of Cardiothoracic Surgery, Baylor College of Medicine, Houston, Tex; and ${ }^{b}$ Department of Advanced Cardiopulmonary Therapies and Transplantation, The University of Texas Health Science Center at Houston, McGovern Medical School, Houston, Tex

Disclosures: Authors have nothing to disclose with regard to commercial support.

Received for publication Feb 9, 2020; accepted for publication Feb 11, 2020; available ahead of print Feb 22, 2020.

Address for reprints: Shuab Omer, MD, Department of Advanced Cardiopulmonary Therapies and Transplantation, The University of Texas Health Science Center at Houston, McGovern Medical School, Houston, TX 77030 (E-mail: shuab.omer@ uth.tmc.edu).

J Thorac Cardiovasc Surg 2022;163:e41-2

$0022-5223 / \$ 36.00$

Copyright (c) 2020 by The American Association for Thoracic Surgery

https://doi.org/10.1016/j.jtcvs.2020.02.054
}

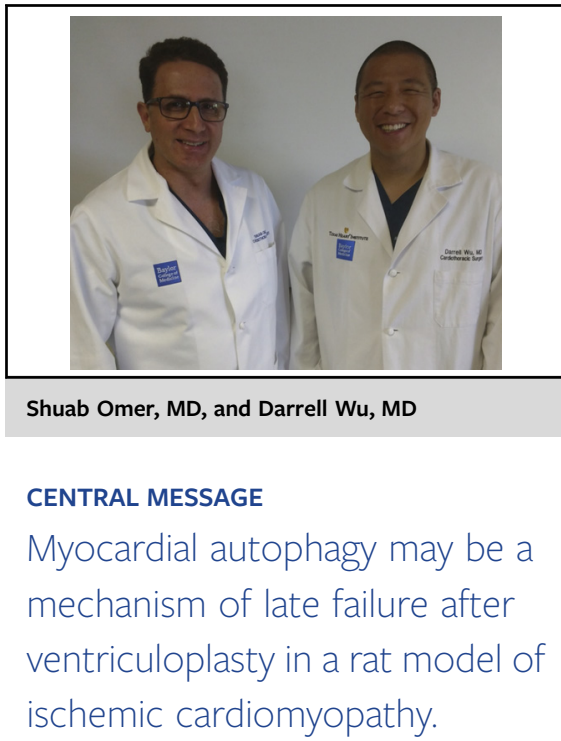

autophagosome marker, was reduced in the early phase compared with control, increased late after LVP, and was further reduced through use of an autophagic inhibitor, 3-MA. Functionally, they found that the left ventricular end-diastolic diameter was smaller early after LVP but then increased late after LVP with use of 3-MA, exhibiting a left ventricular end-diastolic diameter the same as control.

Although this study provides an indication of how autophagy may be related to left ventricular (LV) re-dilatation after LVP in a rat model, there are 3 main points that bear mentioning. First, it is difficult to extrapolate from a rat model to a human, given the altered cardiac vascular anatomy, timing, and surgical technique. More than one half of the rats that underwent LVP died, and almost one third of rats that underwent LAD ligation perished, suggesting that the current analysis is biased. Second, autophagy is a dynamic process (autophagic flux ${ }^{5}$ ), with multiple steps involved that were not analyzed in this simplistic model. By analyzing only the levels of LCS-II, the authors provide only a static picture of a complex system. Third, the use of a nonselective phosphoinositide 3-kinase inhibitor has many more consequences than simply inhibiting autophagy. For instance, phosphoinositide 3-kinase is a main activator of Akt, which has multiple downstream effects, not to mention differential effects on Akt-1 and Akt-2 signaling, which can also lead to altered myocardial metabolism. Furthermore, their use of an inhibitor just 1 day after LVP is curious, given they wanted to examine the effects of LV re-dilatation after LVP. Perhaps this might explain why there wasn't much functional change. 
Nonetheless, despite these limitations, establishing the role of autophagy in LV re-dilatation after LVP is paramount in the effort to eventually develop pharmacologic interventions that can alter myocardial metabolism and remodeling in ischemic cardiomyopathy.

\section{References}

1. Wu D, Zhang K, Hu P. The role of autophagy in acute myocardial infarction. Front Pharmacol. 2019;10:551.
2. Delbridge LMD, Mellor KM, Taylor DJ, Gottlieb RA. Myocardial stress and autophagy: mechanisms and interventional prospects. Nat Rev Cardiol. 2017;14:412-25.

3. Lavandero S, Chiong M, Rothermel BA, Hill JA. Autophagy in cardiovascular biology. J Clin Invest. 2015;125:55-64.

4. Sugimoto S, Shingu Y, Doenst T, Yamakawa T, Asai H, Wakasa S, et al. Autophagy during left ventricular redilation after ventriculoplasty: insights from a rat model of ischemic cardiomyopathy. J Thorac Cardiovasc Surg. 2022;163: e33-40.

5. Toit AD, Hofmeyr JHS, Gniadek TJ, Loos B. Measuring autophagosome flux. Autophagy. 2018;14:1060-71.

\section{See Article page e33.}

\section{Commentary: Follow where the data take you}

\author{
Jakob Vinten-Johansen, PhD
}

Autophagy is a highly regulated process that eliminates misshapen, long-lived, excessive, or damaged proteins or organelles (eg, mitochondria) by lysosomal degradation or "self-digestion." Autophagy is a normal housekeeping process in the baseline heart, but unbalanced autophagyinadequate (heart failure), suppressed, or excessive (ischemia-reperfusion injury, heart failure)-can contribute to cardiac pathology. In some pathologies, autophagy can have either beneficial or deleterious effects and hence presents as a double-edged sword.

In this initial proof-of-concept study, Sugimoto and colleagues ${ }^{1}$ hypothesize that autophagy "plays an important role" in redilatation after left ventriculoplasty (LVP), but they do not hypothesize whether autophagy limits or contributes to redilatation. The authors report that myocardial infarction (MI) was associated with larger early and late left ventricular (LV) diastolic dimensions and myocyte area, and less fractional shortening (FS) relative to a time sham group, thereby confirming the model of MI-induced maladaptive remodeling. Two days post-ventriculoplasty (early changes) LV diastolic dimensions and myocyte area

From the Department of Surgery (Cardiothoracic), Emory University, Atlanta, Ga Disclosures: Author has nothing to disclose with regard to commercial support.

Received for publication Feb 18, 2020; revisions received Feb 18, 2020; accepted for publication Feb 19, 2020; available ahead of print March 4, 2020.

Address for reprints: Jakob Vinten-Johansen, PhD, Professor Emeritus, Department of Surgery (Cardiothoracic), 159 Montauk Ct, Clemmons, NC 27012 (E-mail: jvinten@emory.edu or jvinten@comcast.net).

J Thorac Cardiovasc Surg 2022;163:e42-3

$0022-5223 / \$ 36.00$

Copyright (c) 2020 by The American Association for Thoracic Surgery

https://doi.org/10.1016/j.jtcvs.2020.02.083
Check for updates

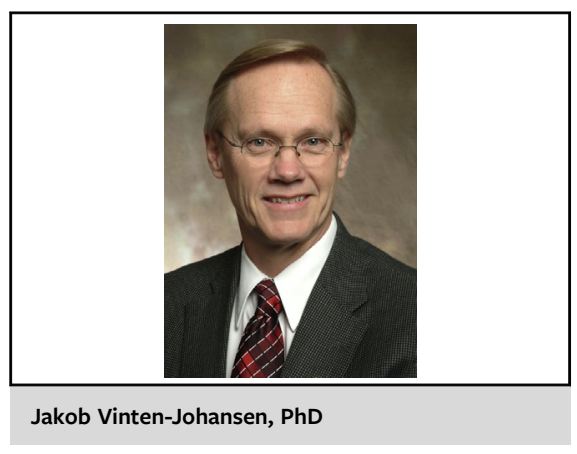

CENTRAL MESSAGE

The first observations in a rat model of post-ventriculoplasty redilatation ventriculoplasty suggest that autophagy is triggered during redilatation, but does it play a deleterious or beneficial role?

were markedly reduced, and fractional shortening (FS) was increased relative to preoperative values. However, after 28 days post-ventriculoplasty, the LV had redilated, and early improvement in FS was lost. A marker of autophagy, LC3-II, decreased early after LVP but increased markedly during the later redilatation period after ventriculoplasty relative to the shams and MI/sham groups, consistent with enhanced autophagy.

This last observation provides the strongest support for the authors' hypothesis. Administration of a phosphoinositide-3 kinase inhibitor (3-MA) for 21 days post-ventriculoplasty to inhibit autophagy was associated with only a slight increase in already dilated LV dimensions, a further reduction in FS, and an increase in myocyte area relative to the MI/LVP group, which strengthens 